\title{
Differential maternal behavior of the rat dam toward natural and foster pups: Implication for nutrition research
}

\author{
JAMES R. MISANIN, DONNA M. ZAWACKI, and WILLIAM G. KRIEGER \\ Susquehanna University, Selinsgrove, Pennsylvania 17870
}

\begin{abstract}
Two experiments were designed to study the retrieval behavior of female rats toward natural and foster offspring. In the first experiment, lactating female rats were introduced into a two-pup choice situation and their behavior was examined. In the second experiment, time to retrieve natural and foster pups was measured. The results indicated that the females showed no preference in the choice situation. They did, however, differentially treat the natural and foster pups once contact with the pup was made. The implication of these findings for nutrition research is discussed.
\end{abstract}

Studies of early undernutrition in rats have typically employed one of three deprivation regimens: (1) removing the infant from the mother so that the infant is without its source of food for some length of time, (2) increasing litter size to the point that the mother cannot supply adequate nutriment to all pups, and (3) underfeeding the mother during gestation and/or lactation, thus decreasing the mother's capability to afford sufficient nutriment to her litter. Though such regimens are quite effective in producing food-deprivation effects, these effects cannot be completely divorced from those produced by alteration of maternal care and social environment which results from the deprivation methodologies themselves.

Slob, Snow, and de Natris-Mathot (1973) have suggested an alternate deprivation regimen to counteract such confounding. Their methodology involved placing rat pups with nonlactating foster mothers previously primed to engage in maternal behavior. Such methodology, it was argued, removes the infant from its food source without drastically altering its social environment. Indeed, these investigators successfully demonstrated that the adult behavior of rats exposed to this deprivation regimen in infancy showed fewer deficits than did that of animals exposed to the typical deprivation regimens.

Implicit in the Slob et al. (1973) methodology is the assumption that foster mothers engage in maternal behaviors which are equivalent to those of natural mothers. There is, however, very little basis for this assumption in the available literature. There is also little evidence to support an assumption to the contrary, although the data of Allin and Banks (1972)

The authors thank Karen E. Jones for her assistance in conducting this research. Requests for reprints should be sent to James R. Misanin, Department of Psychology, Susquehanna University, Selinsgrove, Pennsylvania 17870. led them in that direction. These investigators exposed lactating and nonlactating female rats to recorded vocalizations of pups and found that only lactating females showed a tendency to leave the nest in response to these calls. However, because only $50 \%$ of the lactating females responded, Allin and Banks hypothesized that maternal female rats can distinguish, and may respond selectively to, the distress calls of their own pups.

To test the validity of the assumption implicit in the Slob et al. (1973) methodology, and to examine the implication of the Allin and Banks (1972) hypothesis that maternal female rats can distinguish their own pups from others at a distance, the present study investigated the retrieval behavior of maternal rats toward their own and foster pups.

\section{EXPERIMENT 1}

Using an apparatus and procedure similar to those devised by Young (1965), we examined the choice behavior of lactating female rats towards rat pups. Specifically, we sought to determine if rat mothers would choose their own pups over foster pups in a twopup choice situation, and if they would choose pups (natural or foster) reared by them over pups (their own or other) reared by another dam.

\section{Method}

Subjects. The subjects were albino rats of the Wistar strain born and reared in the Susquehanna University animal colony. Eight lactating female rats and their culled litters served as the subjects. On the day of birth, all litters to be used were culled to four males and four females, and these neonates were toeclipped for identification.

Apparatus. Eight $46 \times 20 \times 15 \frac{1}{2} \mathrm{~cm}$ plywood maternity cages with wire tops were used. A guillotine-door end wall of each cage could be attached to the center of one side of a $60 \times 30 \times 15 \frac{1}{2} \mathrm{~cm}$ plywood open field with a clear acrylic top so that raising the door of the cage provided access to the open 
field. The insides of the cages and open field were painted light gray, and the cage floors were covered with pine shavings. At the end of the open field opposite the guillotine door of the maternity cage, three 9-cm-diam circles spaced $11.5 \mathrm{~cm}$ apart, center to center, were countersunk $6 \mathrm{~mm}$ in a $60 \times 15 \times .6 \mathrm{~cm}$ plywood platform.

A stainless steel box $\left(25 \times 18 \frac{1}{2} \times 13 \mathrm{~cm}\right)$, heated by a $100-W$ incandescent light bulb suspended $28 \mathrm{~cm}$ above its floor, contained pine shavings and was used as a holding cage for infant rats during retrieval tests and during pretest adaptation trials.

Procedure. Lactating females were run in pairs. Mothers whose litters were born within $6 \mathrm{~h}$ of each other were paired. When litters were culled and pups marked for identification, two male and two female pups of one litter of the pair were exchanged for two males and two females of the other litter, so that each mother cared for four natural and four foster pups, two males and two females of each. The infant animals were weighed and dams and litters were transferred to the wooden maternity cages, where they remained, except during test and pretest sessions, until the end of the experiment.

On the day following parturition, lactating females were given four 5-min adaptation trials in the open field with an intertrial interval (ITI) of $5 \mathrm{~min}$. Pups remained in the nest and the door was kept closed. During the ITI, the dam was returned to the maternity cage.

The first two adaptation trials on the following day followed the same procedure. For Trials 3 and 4, however, the pups were removed from the maternity cage and the dam allowed to enter the open field through the guillotine doorway. If she did not enter within $5 \mathrm{~min}$, she was gently pushed through the doorway into the field where, as previously, she was allowed to remain for $5 \mathrm{~min}$.

On the next day, two practice retrieval trials were given with a 5-min ITI. Five minutes before the first trial, pups were moved from the maternity cage to the holding cage and divided randomly into two groups of four. One group was put into the center circle in the open field and the guillotine door was raised. The dam was allowed $10 \mathrm{~min}$ to retrieve the pups after she left the maternity cage. If she did not leave the cage within $5 \mathrm{~min}$, she was gently pushed into the field. If she retrieved all pups within the 10 -min period, the door to the maternity cage was closed and the pups were returned to the holding cage. If she failed to retrieve any or all pups during the $10-\mathrm{min}$ allowed, she was returned to the maternity cage and the pups were returned to the holding cage. The second trial was identical to the first except that the second group of pups was used. Following the second trial, the pups were returned to the holding cage for $5 \mathrm{~min}$.

On each of the 4 following days, eight retrieval trials were given to each dam with a 5-min ITI. All pups were removed from the maternity cage $5 \mathrm{~min}$ before the first trial. On the first four trials, the choices were between same-sex natural and foster pups. A single blind procedure was followed (i.e., the experimenter was unaware of the identity of the pups). Each trial began by placing a natural pup in one end circle in the open field and a foster pup in the other, and opening the guillotine door. The side on which the natural or foster pup appeared was alternated for trials and counterbalanced over days, subjects, and sex of pup. The maximum allowable time to leave the maternity cage was $5 \mathrm{~min}$, after which the dam was gently forced into the field. Once in the field, the maximum allowable time to make a choice was also $5 \mathrm{~min}$. A choice was defined as returning a pup to the maternity cage. If a choice was not made within the time allotted, the mother was returned to the maternity cage to await the next trial. After a choice was made or the trial terminated, both pups were returned to the holding cage. The identification mark of the pup chosen and the location of the circle (left-right) were recorded.

During the last four trials, the choices were between natural (N) or foster (F) pups reared by the dam making the choice (n) and her offspring $(N)$ or other offspring $(F)$ raised by the other female of the pair (f). Thus, the four choices were between:
$\mathrm{Nn}$ and Nf, Nn and Ff, Fn and Nf, and Fn and Ff. The experimenter was unaware of the N-F identities, and male and female pups were used on alternate days. Otherwise, the procedure was the same as for the first four trials.

\section{Results and Discussion}

Inspection of the dams' choice on the first four daily trials indicated no systematic preferences. Percentage choices of natural offspring on each of the four trials, collapsed over days, were $38,54,56$, and 56 , respectively; on each of the 4 days, collapsed over trials, percentages were $46,60,54$, and 48 , respectively. Overall preference for natural offspring was $51 \%$. An overall preference was determined for each dam and a binomial test was applied to the number of animals in the sample showing a preference for their natural pups. The results indicated no significant difference between the probability of selecting a natural vs. a foster pup in this two-pup choice situation $(p=.637)$. The dams rarely sampled (e.g., approached and sniffed) both pups before returning one to the nest. More typically, they went directly from the cage to a pup and back again. Even choice of side appeared random. Two subjects, however, showed a strong tendency to go to the right side of the field. The overall percentage runs to the right side with and without the data of these two subjects were 62 and 53, respectively.

Inspection of the dams' choices over the last four daily trials also indicated that there were no significant preferences. The overall percentage preference for natural offspring was 48 ; that for pups reared by the dam making the choice was 58. Percentages for the $\mathrm{Nn}, \mathrm{Nf}, \mathrm{Fn}$, and Ff choices were 26, 21, 32, and 21, respectively. Although preference for the foster pup (Fn) was, by far, the greatest, it did not approach significance by a binomial test. Sex did not play a prominent role in the status (natural, foster, etc.) of the offspring retrieved.

\section{EXPERIMENT 2}

In Experiment 1 we found that the choice behavior of the lactating female rat in a two-pup choice situation was not greatly influenced by the status of the pup. It is thus possible that the female rat cannot discriminate between natural and foster offspring at a distance (cf. Allin \& Banks, 1972). In Experiment 2 we sought to examine this possibility and to again test the assumption implicit in the Slob et al. (1973) methodology by analyzing the behavior of the rat dam before and after pup contact in a retrieval situation.

\section{Method}

Subjects. The subjects were four primiparous and four multiparous Wistar albino rats.

Apparatus. The maternity and holding cages were those used in Experiment 1. The open field was the same as that used in Experiment 1 except that a transparent red acrylic covering replaced the clear acrylic one on alternate trials.

Procedure. On the day of parturition, each female's litter was culled to two males and two females. Added to this culled 
litter were two males and two females from another litter born on the same day. All pups were toe-clipped for identification and transferred with the dam to the wooden maternity cage.

The pretest adaptation and retrieval practice trials on the 3 days following parturition were identical to those described in Experiment 1 except that the red acrylic covering for the open field was used on alternate trials.

On each of the 4 following days, eight retrieval tests were administered to each dam; ITI was $5 \mathrm{~min}$. All pups were moved to the holding cage $5 \mathrm{~min}$ before the first trial and returned to the maternity cage $5 \mathrm{~min}$ after the last trial. A single blind procedure was followed on all trials. Half of the subjects began their trials with the red acrylic field covering in place and half with the clear. The order was alternated for subjects over days. A trial began by placing a rat pup in the center circle in the field and raising the guillotine door of the maternity cage. The pup status order of presentation was counterbalanced for subjects over days, trials, and sex of pup. Time measures [time to leave the maternity cage (all four feet in the field), time to pick up the pup, and time to return the pup to the maternity cage] were recorded to the nearest $.1 \mathrm{sec}$. The time allowed to retrieve the pup after opening the guillotine door was 300 sec. If the female did not retrieve the pup within that time, the trial was terminated and a latency of $300 \mathrm{sec}$ assigned. The pup was returned to the holding cage and the female secured in the maternity cage.

\section{Results and Discussion}

A split-plot factorial (SPF-2.2224) analysis of variance (Kirk, 1968) was performed on the reciprocal (speed) of each of the three time measures: The factors under consideration were parity (primiparous, multiparous), sex of pup, field covering (red, clear), status of offspring (natural, foster), and days.

For the first measure, time to leave the maternity cage, field covering yielded the only significant main effect $[F(1,6)=11.63, p<.02]$. That this factor was significant was not surprising. Rats show both a fear reaction to an open field and a preference for darkness. Red not only has a low brightness value for rats (Munn, 1950), but the red covering decreased the illumination in the field from 7 to $2 \mathrm{fc}$. The daily speed with which the rats entered the open field also increased at a faster rate under the red covering than under the clear $[\mathrm{F}(3,18)=3.45, \mathrm{p}<.04]$. The daily speeds were .29 , $.51, .62$, and .71 for the red covering and $.26, .28, .43$, and .38 for the clear. The Parity by Sex interaction was also significant $[F(1,6)=15.89, p<.01]$. This may be a spurious finding since neither parity, sex of pup, nor their interaction significantly affected the speed with which the dam picked up the pup after entering the field. With regard to the second measure, time to pick up the pup, field covering was the only significant factor $[F(1,6)=16.68, p<.01]$, and it failed to interact with any other. The dam picked up the pup faster under the clear cover than under the red one; the respective speeds were .30 , and .18 . We assume the dam found the pup to be in a less threatening or fearful situation under the red cover.

The results of the analyses of the first two measures support the results of Experiment 1 in indicating that female rats do not discriminate between natural and foster offspring from a distance. However, the results of the analysis of the third measure, speed of returning the pup to the maternity cage, indicate that the female rat does discriminate between natural and foster offspring once contact with the pup is made. Here, status of pup yielded the only significant main effect $[F(1,6)=15.72$, $p<.01]$. Means indicated that foster pups were returned significantly faster than natural pups; the respective speeds were .72 and .56. The Parity by Sex of Pup by Covering by Pup Status interaction was also significant $[F(1,6)=23.88, p<.01]$. Inspection of cell means indicated that multiparous females returned natural female pups to the maternity cage faster than they did the foster pups when the field covering was clear. Under all other conditions, foster pups were returned faster.

\section{GENERAL DISCUSSION}

It is highly unlikely that a treatment that has drastic and long-lasting effects on the structural development of the brain (e.g., Altman \& McCrady, 1972; Benton, Moser, Dodge, \& Carr, 1966) and other organs and systems (cf. Winick \& Noble, 1967) would have little or no effect on the functional aspects of these organs and systems. Yet, this is what the results of numerous studies on the effects of infantile undernutrition on learned behavior would lead us to believe. Guthrie (1968), for example, found no significant effect of early malnutrition on adult rats' acquisition of a shuttlebox avoidance response. Similarly, Smart and Dobbing (1972) found no difference in the passive avoidance behavior of normal and previously underfed young (30-31 days of age) rats. Even deprivation during gestation, a time when organs and systems are particularly vulnerable to deprivation effects, had no significant effect on the behavior of rats in a Hebb-Williams maze (Ottinger \& Tanabe, 1968). Slob et al. (1973), who also found no effect of early undernutrition on the behavior of adult rats on two complicated, shock-motivated, discrimination tasks, maintained that the behavioral deficits found by other experimenters resulted from poor maternal care and the absence of normal social interaction rather than from undernutrition per se.

It seems much more likely that, either intentionally (e.g., Vore \& Ottinger, 1970) or inadvertently, experimental procedures can be adopted that will counteract or compensate for the deleterious effects of infantile undernutrition. The adoption of such procedures could thus account for the failure to observe behavioral deficits in animals deprived of food in infancy. Such an inadvertent procedure is suggested in the results of the present study. In all of the above studies, a fostering technique was employed to avoid effects of maternal, social, and environmental deficiencies inherent in the three typical infant deprivation regimens. The results of the present study suggest, however, that the maternal behaviors of foster mothers are not equivalent to those of natural mothers. Foster charges were returned more quickly to the nest than natural offspring under nearly all conditions. Thus, if fostering leads to more maternal attention and stimulation than are provided by the natural mother, then this increased maternal stimulation may serve the same function as environmental stimulation (e.g., Levitsky \& Barnes, 1972; Tanabe, 1972; Wells, Geist, \& Zimmermann, 1972) in remediating behavioral deficiencies produced by undernutrition, and, hence, account for the failure of the above-mentioned studies to show a deprivation-induced behavioral deficit. Thus, further research is needed to determine if feeding, grooming, and other maternal behaviors of foster mothers differ qualitatively or quantitatively from those of natural mothers. 


\section{REFERENCES}

Allin, J. T., \& Banks, E. M. Functional aspects of ultrasound production by infant albino rats (Rattus norvegicus). Animal Behaviour, 1972, 20, 175-185.

Altman, J., \& MCCRADY, B. The influence of nutrition on neural and behavioral development: IV. Effects of infantile undernutrition on growth of the cerebellum. Developmental Psychobiology, 1972, 5, 111-122.

Benton, J. W., Moser, H. W., Dodge, P. R., \& Carr, S. Modification of the schedule of myelination in the rat by early nutritional deprivation. Pediatrics, 1966, 38, 801-807.

Guthrie, H. A. Severe undernutrition in early infancy and behavior in rehabilitated albino rats. Physiology and Behavior, 1968, 3, 619-623.

KIRK, R. E. Experimental design: Procedures for the behavioral sciences. Belmont: Brooks/Cole, 1968.

Levitsky, D. A., \& Barnes, R. H. Nutritional and environmental interactions in the behavioral development of the rat: Long-term effects. Science, 1972, 176, 68-71.

Munn, N. L. Handbook of psychological research on the rat. Boston: Houghton Mifflin, 1950.

Ottinger, D. R., \& TANABE, G. Maternal food restriction: Effects on offspring behavior and development. Developmental Psychobiology, 1968, 2, 7-9.

Slob, A. K., SNow, C. E., \& DE Natris-Mathot, E
Absence of behavioral deficits following neonatal undernutrition in the rat. Developmental Psychobiology, 1973, 6, 177-186.

SmarT, J. L., \& DobBing, J. Vulnerability of developing brain: IV. Passive avoidance behavior in young rats following maternal undernutrition. Developmental Psychobiology, 1972, 5, 129-136.

TANABE, G. Remediating maze deficiencies by the use of environmental enrichment. Developmental Psychology, 1972, 7, 224.

Vore, D. A., \& Ottinger, D. R. Maternal food restriction: Effects on offspring development, learning, and a program of therapy. Developmental Psychology, 1970, 3, 337-342.

Wells, A. M., Geist, C. R., \& Zimmermann, R. R. Influence of environmental and nutritional factors on problem solving in the rat. Perceptual and Motor Skills, 1972, 35, 235-244.

Winick, M., \& Noble, A. Cellular response with increased feeding in neonatal rats. Nutrition, 1967, 91, 179-182.

YounG, R. D. Influence of neonatal treatment on maternal behavior: A confounding variable. Psychonomic Science, 1965, 3, 295-296.

(Received for publication June 16, 1977.) 